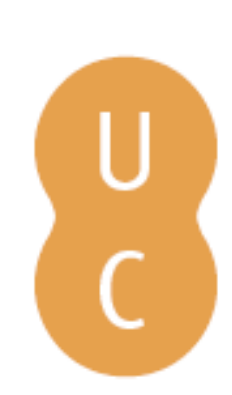

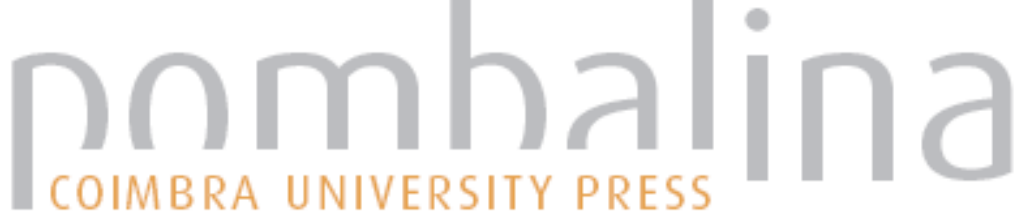

\section{Comunicação de riscos e Jornalismo: considerações sobre esta relação a partir das mudanças do clima}

\author{
Autor(es): $\quad$ Loose, Eloisa Beling \\ Publicado por: Imprensa da Universidade de Coimbra; RISCOS - Associação \\ URL \\ persistente: URI:http://hdl.handle.net/10316.2/34794 \\ DOI: $\quad$ DOI:http://dx.doi.org/10.14195/978-989-96253-3-4_2 \\ Accessed : $\quad$ 26-Apr-2023 11:25:56
}

A navegação consulta e descarregamento dos títulos inseridos nas Bibliotecas Digitais UC Digitalis, UC Pombalina e UC Impactum, pressupõem a aceitação plena e sem reservas dos Termos e Condições de Uso destas Bibliotecas Digitais, disponíveis em https://digitalis.uc.pt/pt-pt/termos.

Conforme exposto nos referidos Termos e Condições de Uso, o descarregamento de títulos de acesso restrito requer uma licença válida de autorização devendo o utilizador aceder ao(s) documento(s) a partir de um endereço de IP da instituição detentora da supramencionada licença.

Ao utilizador é apenas permitido o descarregamento para uso pessoal, pelo que o emprego do(s) título(s) descarregado(s) para outro fim, designadamente comercial, carece de autorização do respetivo autor ou editor da obra.

Na medida em que todas as obras da UC Digitalis se encontram protegidas pelo Código do Direito de Autor e Direitos Conexos e demais legislação aplicável, toda a cópia, parcial ou total, deste documento, nos casos em que é legalmente admitida, deverá conter ou fazer-se acompanhar por este aviso.

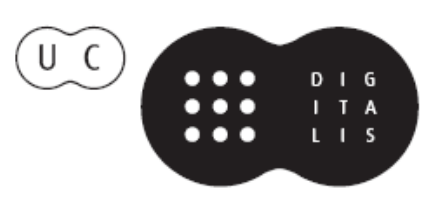



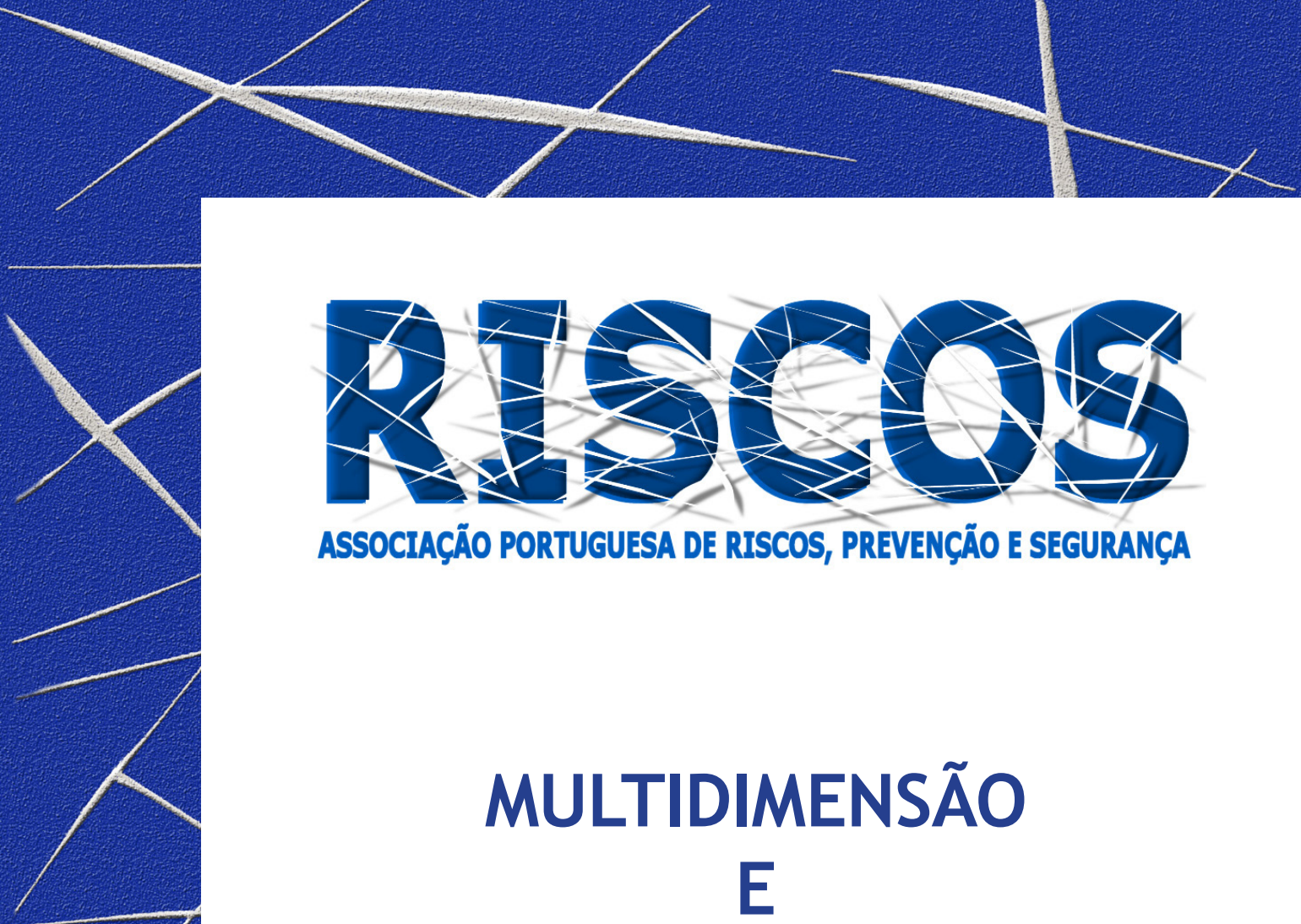

ASSOCIAÇÃO PORTUGUESA DE RISCOS, PREVENCCÃO E SEGURANÇA

MULTIDIMENSÃO

E
TERRITÓRIOS DE RISCO

III Congresso Internacional

I Simpósio Ibero-Americano

VIII Encontro Nacional de Riscos

Guimarães

2014 


\title{
COMUNICAÇÃO DE RISCOS E JORNALISMO: CONSIDERAÇÕES SOBRE ESTA RELAÇÃO A PARTIR DAS MUDANÇAS DO CLIMA
}

\author{
Eloisa Beling Loose \\ Programa de Pós-Graduação em Meio Ambiente e Desenvolvimento da Universidade Federal do Paraná. \\ Bolsista CAPES - proc. $\mathrm{n}^{\circ}$ 99999.003712/2014-01 \\ eloisa.loose@gmail.com
}

\begin{abstract}
RESUMO
O objetivo do trabalho é evidenciar o papel do jornalismo no âmbito da comunicação de riscos, a partir dos riscos decorrentes das mudanças climáticas. Além de uma discussão teórica, o artigo evidencia a forma como o jornal Gazeta do Povo, impresso de maior circulação no estado do Paraná, Brasil, trata dos riscos climáticos durante as divulgações do $1^{\circ}$ Relatório Brasileiro de Mudanças Climáticas e do $5^{\circ}$ Relatório do Painel Intergovernamental de Mudanças Climáticas (IPCC, na sigla em inglês). Para tanto, realiza-se um mapeamento das notícias que articulem os riscos atrelados às alterações do clima no período já mencionado e uma análise de seus enquadramentos, com o fim de verificar de que modo este jornalismo tem retratado o assunto e, consequentemente, participado na comunicação dos riscos climáticos.
\end{abstract}

Palavras-chave: comunicação de risco; jornalismo; mudanças climáticas

\section{Introdução}

A ideia deste paper é enfatizar a relação existente entre a atividade jornalística e seu papel no âmbito da comunicação de riscos, tendo em vista seu alcance e potencial para disseminar e promover ações de enfrentamento, sejam elas de prevenção, mitigação ou adaptação. Além de uma breve discussão teórica, apresenta-se a forma como o jornalismo do impresso Gazeta do Povo tratou dos riscos climáticos nas divulgações do $1^{\circ}$ Relatório Brasileiro de Mudanças Climáticas e do $5^{\circ}$ Relaório do Painel Intergovernamental de Mudanças Climáticas, ocorridas no segundo semestre de 2013.

Para a análise foi realizado um mapeamento das notícias que articulam - de forma explícita ou implícita - os riscos atrelados às mudanças climáticas nos períodos já citados e uma análise de seus enquadramentos. A intenção foi verificar de que modo o jornalismo da Gazeta do Povo tem contribuído na comunicação dos riscos climáticos, já que é o maior diário que circula em Curitiba, Paraná, e, portanto, possui grande alcance na formação de opinião da população local.

\section{Comunicação de risco}

A comunicação e o acesso à informação qualificada sobre riscos são apontados por vários especialistas como o ponto inicial necessário para que haja prevenção de riscos (Salazar Vindas, 1999). Também durante e após os desastres seu papel tem ganhado destaque para conduzir processos de reconstrução, mitigação dos danos e de governança dos riscos. Mais do que apenas transmitir informações e permitir o diálogo com diferentes sujeitos atrelados aos riscos (afetados, especialistas, poder público e demais envolvidos), o processo de comunicação atua na construção de determinadas percepções e significados que podem facilitar ou dificultar a gestão integral dos riscos. Aqui, a comunicação de risco estudada é aquela atrelada aos riscos relacionados às mudanças climáticas, sendo assim, parte da gestão e governança ambiental, de forma ampla, e climática, de forma mais específica. 
A comunicação de risco pode ser entendida como "[...] o processo de troca entre a comunidade acadêmica, os profissionais das agências reguladoras, os grupos de interesse e a o público em geral, em que se considera como melhor avaliar e gerenciar os riscos” (Powell \& Leiss, 2005:92). A ênfase na comunicação de riscos como "[...] importante instrumento de demoratização do processo de tomada de decisão diante de um determinado risco" (UFSC, 2012:22) evidencia que esta extrapola os meios de comunicação, ainda que sua abrangência esteja, muitas vezes, diretamente relacionada a eles em razão de seu alcance social.

Serra (2009), ao tratar do tema, avalia que os media desempenham pelo menos três funções: 1) agendamento e enquadramento dos riscos, de modo a nos dizer sobre o que pensar e como pensar a respeito; 2) intermediação, pois os media relacionam os poderes instituídos aos cidadãos; e 3) legitimação da tomada de decisões, na medida em que funcionam como um fórum em que as questões relativas aos riscos são analisadas e discutidas sob diferentes óticas. Em razão disso parte-se do pressuposto que a forma pela qual os riscos são apresentados pelo jornalismo, para além de formatar uma perspectiva (evidenciando alguns aspectos e omitindo outros), permitem que os leitores possam enfrentar os riscos de formas diferentes (mais ou menos ativas).

\section{Jornalismo "de riscos"}

Mesmo que pertencente ao campo da comunicação, o jornalismo possui lógicas próprias que, nem sempre, contribuem para o cumprimento dos objetivos da comunicação de risco. As rotinas produtivas, pressionadas sempre pelo pouco tempo, assim como a busca por fatos que se encaixem nos valores-notícia e rendam audiência, tendem a dar destaque apenas quando a ameaça já se tornou desastre, tragédia. Notícias sobre prevenção, adaptação e mitigação não costumam entrar na pauta com a mesma frequência do que as situações de emergência, justamente por não terem o mesmo apelo do factual e do impacto às vidas humanas.

No entanto, mesmo sem a intenção de se envolver com a gestão dos riscos, a imprensa contribui (positiva ou negativamente) para o processo na medida em que catástrofes, desastres ou anúncios de riscos tornam-se pauta na imprensa. A visibilidade que o tema ganha na esfera pública através da cobertura jornalística e o modo com o qual o tema é abordado refletem na informação (ou desinformação) do público em relação ao fato. O envolvimento e o enfrentamento dos riscos está intimamente ligado à comunicação que se faz dos riscos (Giulio, 2010) e o jornalismo é um importante vetor na disseminação de estratégias que estabeleçam relações entre os que avaliam e aqueles que vivenciam o risco. Para que haja gestão dos riscos e também promoção da governança de baixo para cima é preciso empoderar os leitores com informações contextualizadas e formas de combater as consequências do problema que é posto.

\section{Breve análise da divulgação de relatórios sobre Mudanças Climáticas}

$01^{\circ}$ Relatório Brasileiro de Mudanças Climáticas, divulgado na primeira quinzena de setembro, não teve muita repercussão no jornal analisado, tendo apenas duas notícias publicadas a respeito. Já o $5^{\circ}$ relatório do IPCC, que foi divulgado no dia 27 do mesmo mês, começou a render notícias no dia 20 e seguiu divulgando seus desdobramento até 02 de outubro, totalizando 11 textos sobre este relatório e 13 dos dois. Onze destes são oriundos de agências de notícias nacionais e internacionais.

A análise realizada neste trabalho buscou identificar como os riscos climáticos (entendidos como as consequências do fenômeno derivados de perigo calculável ou acontecimento previsível 
fruto das atividades humanas) se fazem presentes nestes momentos de divulgação científica sobre o tema mudanças climáticas. Para tanto, utiliza-se o conceito de frame ou enquadramento de modo a operacionalizar como os riscos são apresentados nas notícias. Adota-se o entendimento de Entman (1993), que atrela os frames jornalísticos diretamente aos textos e usa o verbo to frame para indicar a seleção de alguns aspectos da realidade percebida e fazê-los mais proeminentes em um texto, de maneira a promover definições particulares de um problema, interpretações causais, avaliações morais e/ou recomendações para o tratamento do assunto descrito.

Logo, investiga-se nos textos citados a recorrência da apresentação de tais riscos (aumento de temperatura, secas prolongadas, impactos na agricultura, etc.) e o lugar que ele ocupa na notícia (título e subtítulo, lead e texto), atentando que a força de seu destaque é diretamente atrelada ao lugar onde o risco é apresentado (nos títulos recebe mais destaque, no lead um pouco menos e no texto a força da saliência é menor ainda). A tabela abaixo busca sintetizar a visão geral dos riscos das notícias analisadas:

\begin{tabular}{|c|c|c|c|c|}
\hline & $\begin{array}{l}\text { Títulos } \\
\text { (enquadramentos muito } \\
\text { fortes) }\end{array}$ & $\begin{array}{l}\text { Subtítulos } \\
\text { (enquadramentos muito } \\
\text { fortes) }\end{array}$ & $\begin{array}{l}\text { Leads } \\
\text { (enquadramentos fortes) }\end{array}$ & $\begin{array}{l}\text { Restante dos textos } \\
\text { (enquadramentos fracos) }\end{array}$ \\
\hline $\begin{array}{l}\text { Apresenta a } \\
\text { palavra "risco" }\end{array}$ & $\begin{array}{l}\text { Apenas um texo: "Aque- } \\
\text { cimento põe em risco } \\
\text { até } 57 \% \text { das espécies de } \\
\text { árvores" }\end{array}$ & & & $\begin{array}{l}\text { Apenas um texto (o mes- } \\
\text { mo do título): "Duas ou- } \\
\text { tras pesquisas indicam o } \\
\text { risco de danos causados } \\
\text { pelo aquecimento [...]" }\end{array}$ \\
\hline $\begin{array}{l}\text { Apresenta riscos } \\
\text { sem mencionar } \\
0 \text { termo (expõe } \\
\text { efeitos calculá- } \\
\text { veis derivados das } \\
\text { atividades huma- } \\
\text { nas - neste caso } \\
\text { ligado às emissões } \\
\text { de gases de efeito } \\
\text { estufa) }\end{array}$ & $\begin{array}{l}\text { Em oito. Exemplos: “Tem- } \\
\text { peratura deve subir até } 6{ }^{\circ} \\
\text { C no Brasil até o final do } \\
\text { século"; “IPCC: Amazônia } \\
\text { pode perder 70\% da área } \\
\text { caso estação seca aumen- } \\
\text { te”; “Cientistas concluem } \\
\text { que planeta está amea- } \\
\text { çado" }\end{array}$ & $\begin{array}{l}\text { Em sete. Exemplos: } \\
\text { “Concentração de CO2 } \\
\text { na atmosfera chegou a } \\
40 \% \text { agravando o aque- } \\
\text { cimento da Terra"; “Au- } \\
\text { mento médio de } 2,5^{\circ} \mathrm{C} \\
\text { na temperatura do país } \\
\text { até o ano de } 2100 \text { vai } \\
\text { alterar o regime de chu- } \\
\text { vas, causando impactos } \\
\text { econômicos e sociais" }\end{array}$ & $\begin{array}{l}\text { Em nove. Exemplos: “[...] } \\
\text { trazendo consequências } \\
\text { como alterações no regi- } \\
\text { me de chuvas; aumento } \\
\text { ou diminuição do volu- } \\
\text { me dos rios; impactos na } \\
\text { agricultura, pesca e setor } \\
\text { hidrelétrico”; “A sobrevi- } \\
\text { vência [...] das espécies } \\
\text { de árvores [...] será ame- } \\
\text { açada de extinção [...]” }\end{array}$ & $\begin{array}{l}\text { Em nove. Exemplos: "Com } \\
\text { mais CO2 e temperaturas } \\
\text { mais altas, o derretimen- } \\
\text { to de geleiras se intensi- } \\
\text { fica, assim como o nível } \\
\text { dos oceanos aumenta e a } \\
\text { ocorrência de eventos cli- } \\
\text { máticos extremos se torna } \\
\text { mais frquente"; "A eleva- } \\
\text { ção da temperatura deve } \\
\text { ser acompanhada por di- } \\
\text { versas mudanças climáti- } \\
\text { cas, como ondas de calor, } \\
\text { inundações e secas" }\end{array}$ \\
\hline
\end{tabular}

Assim, embora a apresentação do risco não seja explícita, percebe-se que em todas as matérias, de forma mais ou menos forte, se fazem presentes, trazendo a ideia de ameaça, de afetação, de impacto. Mesmo que a maioria das notícias tenha enquadramentos fortes e fracos (e não muito fortes), é possível afirmar que os riscos climáticos estejam sendo recorrentemente acionados na divulgação deste tipo de relatórios, ainda que os títulos e subtítulos, neste caso, tenham dado preferência à abordagem da certeza de que o homem esteja contribuindo para o aquecimento global, como frisou o último relatório do IPCC.

\section{Conclusão}

Verifica-se que no período estudado a Gazeta do Povo mostrou-se preocupada em salientar os riscos climáticos de modo a chamar atenção de seus leitores para a questão das mudanças climáticas. Goiricelaya (1998) afirma que é um princípio democrático o de informar a sociedade sobre os acontecimentos que colocam em risco às pessoas, seus efeitos e qual é a resposta que 
está sendo tomada em relação a eles. Neste sentido, constata-se que o jornal publicou notícias sobre os relatórios atentando para alertar a população sobre possíveis consequências das mudanças do clima e o papel que a atividade antropogênica assume neste cenário.

0 trabalho realizado pelos meios de comunicação e, especialmente, pelo jornalismo, que é o subcampo responsável pelos acontecimentos factuais, pela informação, tem crucial relevância na medida em que pode participar da educação do público sobre riscos e desastres, no momento de alerta, e também na discussão sobre os sistemas de resposta e prevenção aos riscos. A forma como a imprensa medeia as situações de riscos interfere na forma pela qual os cidadãos vão perceber e enfrentar tal realidade.

Nesse sentido, o jornalismo "de riscos" coloca-se como parte do processo de gerenciamento dos mesmos, informando a população das ameaças que estão postas, mas também das possibilidades que cada um tem para superá-las ou contorná-las. Estudos mostram que, embora o tema mudanças climáticas se apresente como incerto, difuso e, muitas vezes, muito maior que o indíviduo - o que prejudica seu enfrentamento -, aproximar as possíveis perdas trazidas por este fenômeno do cotidiano do leitor pode gerar outros movimentos de ação mais responsáveis (Morton et al., 2011). No caso da Gazeta do Povo, observou-se que os riscos, ainda que presentes em todas as notícias, são apresentados de forma bastante distante, sendo necessário construir relações que interliguem o aspecto global com a realidade local de modo a tornar tais riscos mais perceptíveis à população.

\section{Bibliografia}

Entman, Robert. (1993). Framing: Toward Clarification of a Fractured Paradigm. Journal of Communication, 43 (4): p.51-8.

Giulio, Gabriela Marques di; Figueiredo, Bernardino; Costa Ferreira, Lúcia da; Araújo dos Santos, José Ângelo Sebastião. (2010). Comunicação e Governança de Riscos: a experiência brasileira em áreas contaminadas por chumbo. Ambiente \& Sociedade, v. XIII, n. 2, Campinas- SP, p. 283-297.

Goiricelaya, Ernesto. (1998). Desastres y medios de comunicación (El caso de Biescas. Agosto de 1996). Gallarta: Emergencia 112.

Powell, Douglas; Leiss, William. (2005). Um diagnóstico das falhas de Comunicação sobre Riscos. In: Massarani, Luisa; Turney, Jon; Castro Moreira, Ildeu de. (orgs). Terra Incógnita - a interface entre ciência e público. Rio de Janeiro: FIOCRUZ, p.183-201.

Salazar Vindas, Sandra. (1999). Guía para la comunicación social y la prevención de

desastres: "La prevención de desastres comienza con la información" (Taller regional sobre comunicación social y prevención de desastres América Latina) / Sandra Salazar Vindas (org.) - 1a. ed. - San José, C.R.: Secretaría DIRDN, unidad para América Latina y el Caribe. Disponível em: <http://helid. digicollection.org/en/d/Jops02/2.1.html>. Acesso em: 05 maio 2014.

Serra, Paulo. (2009). A mediatização dos riscos: o caso dos riscos ambientais.

Disponível em: < http://www.bocc.ubi.pt/pag/bocc-serra-mediatizacao.pdf>. Acesso em 28 de julho de 2014.

Universidade Federal de Santa Catarina (UFSC). (2012). Promoção da cultura de riscos de desastres: relatório final / Centro Universitário de Estudos e Pesquisas sobre Desastres. - Florianópolis: CEPED. 